\title{
Incidence of liver fluke infestation and pathological examination in sheep (Ovis aries) in Mirpur Azad Jammu and Kashmir
}

\author{
Shahzad Akbar Khan ${ }^{1 *}$, Naveed Ahmed ${ }^{1}$ and Muhammad Tarique \\ Tunio $^{2}$ \\ 1. Department of Pathobiology, Faculty of Veterinary \& Animal Sciences, University of the Poonch, Rawalakot- \\ Pakistan \\ 2. Department of Agricultural Sciences, Allama Iqbal Open University Islamabad-Pakistan \\ Corresponding author's email: shahzadakbar@upr.edu.pk \\ Citation \\ Shahzad Akbar Khan, Naveed Ahmed and Muhammad TariqueTunio. Incidence of liver fluke infestation and \\ pathological examination in sheep (Ovis aries) in Mirpur Azad Jammu and Kashmir. Pure and Applied Biology. \\ Vol. 8, Issue 1, pp750-761. http://dx.doi.org/10.19045/bspab.2019.80017
}

\begin{tabular}{llll}
\hline \hline Received: 27/11/2018 & Revised: 21/01/2019 & Accepted: 22/01/2019 & Online First: 25/01/2019 \\
\hline \hline
\end{tabular}

\section{Abstract}

The study was carried out to examine the incidence of liverfluke infestation and pathological examination in sheep in Mirpur Azad Jammu \&Kashmir. Abattoir and butchers shops were regularly monitored and 200 animals were examined before slaughter and 200 blood and liver samples were collected for biochemical, gross and histopathological study. On the basis of age of animals they were divided into young and adult age group having 100 animals in each group.A subjective evaluation of the gross lesions were performed based on the enlargement of liver, pale discoloration, friability, hemorrhages, discovery of extent of flukes, bile duct obstruction and cholangitis. The cumulative score of gross lesions in adult sheep was quite higher as compared to young sheep.Study has revealed that there was increase in the serum level of glucose, urea, creatinine, triglycerides, ALT, AST, ALP and GGT in adult group of sheep whereas there was apparent decrease of protein in adult sheep. However, in sheep of young age group all the serum biochemical parameters are unaffected. This study has showed that biochemical profile including blood glucose, liver enzymes (AST, ALT, ALP, GGT), urea and creatinine were elevated appreciably $(\mathrm{P}<0.05)$ and there was significantly decrease of total protein $(\mathrm{P}<0.05)$ in infected adult sheep in comparison with young age sheep. Microscopic changes revealed in the study have demonstrated structural changes in parenchyma and billiary tract. Histopathologically, atrophy, death of fatty tissues, multiple areas of death of hepatocytes, inflammation of liver, bile duct fibrosis and death of parenchyma were also examined in some cases of chronic fasciolosis.

Keywords: Biochemical; Fascioliasis; Gross pathology; Necrosis; Seroepidemiology

Introduction

Livestock is a backbone of Pakistan's economy. Role of livestock is very important in the economy of Pakistan from very basic. Livestock entails backbone in the uplift of rural peoples. About 62\% population of 
Pakistan is residing in rural areas and is engaged in one way or other in agriculture for their well being. In order to reduce poverty livestock has a major role as a driving engine for alleviating poverty from Pakistan. As Economic survey of Pakistan 2013 -2014, the share of livestock contributes about $11.8 \%$ to national GDP which shows an increasing trend of almost 2.7 percent as compared to preceding year. The domestic animals include cattle, buffalo, sheep, goat, camels, horses, asses and mules and they produce milk, meat, wool, hair, bones, fat, blood, eggs, hides, and sins. Meat and milk are two important products of animals for satisfying demends of human being. Mutton is produced from sheep and goat. Different types of diseases of sheep has been encountered, of these fascioliasis is responsible for major losses in terms of meat by damaging the major organs of the body in the form of liver and lungs[1].[2] have studied huge losses by Fasciolagigantica in many parts of the world. The occurrence of fascioliasis is notcommon in the countryespecially in the province of Balochistan where farmers drive their major engine of economy from sheep farming in rural areas [3]. Damges in the form of losses has also been noted in sheep and cattle by [4]. These is a huge list of economic losses caused by fasciolosis which may include condemnation of livers partially or wholly. As fascioliasis occurrence depends on climatic condition, development of snails as a intermediate host. As there are other losses in the form of retarded growth, less weight gain, less utilization of feed and quality of meat and milk also affected, such losses are difficult to quantify [5-7]. Keeping in view the above fact this study is focused on epidemiology and gross pathology of fascioliasis.

\section{Materials and methods} Study area
All study was conducted in district Mirpur of Azad Jammu and Kashmir. In mirpur there is a lot of potential and work can be done in improving the health status of sheep. This study is an effort explores the health problem associated with Fasciola Spp. in sheep.For the study histopathological examinations of liver of sheep, for biochemical analysis blood samples of sheep were collected.

\section{Survey of abattoirs and butchers}

Different abattoir and slaughterhouses were visited for prevalence of fascioliasis in district Mirpur Azad Jammu and Kashmir from sheep having different ages. The blood was collected from fascioliasis infected sheep similarly infected livers and gall bladders were also collected in $10 \%$ formalin from sheep brought in slaughterhouse for slaughter.

\section{Samples}

For the study 200 blood samples were collected from sheep before slaughter, similarly 200 livers were also collected from sheep after slaughter. According to age of sheep, animals were separated in two groups, as the age was determined on the number of teeth appearing at different stages of life.one was adult group and other was young group having 100 animals in each group. The grossly affected livers from sheep of different ages were collected from the slaughterhouse. The livers were examined externally and internally (the lobes, gall bladder and bile ducts) for the presence of parasites, and other lesions; nodules abscesses, hydatid cysts, areas of necrosis, fibrosis, congestion and/or haemorrhage, calcification, adhesion, tumor and any other pathologic changes.

\section{Macroscopic examination}

The livers were examined externally and internally for the presence of parasites, nodules abscesses, tumors, fatty change, calcifications, necrosis, fibrosis, pigmentation and hepatitis. After slaughter, visual examination of carcasses and organs 
was done with keen attention being directed to livers.

\section{Histo pathological examination}

At slaughter house gross lesions in livers of different age group animals were carefully recorded. The livers collected were scored for gross lesions. Representative samples were collected in $10 \%$ neutral buffered formalin for histopathological examination. Tissues were passed from different chemicals and after that embedded in paraffin wax, section of 4 to 5 um was made with help of microtome and mounted on clean glass slides. Histopathology was performed according to method described by [8].Tissues were stained with $\mathrm{H} \& \mathrm{E}$ and examined under light microscope. Diagnosis of all the samples was performed in the laboratory of pathology, Department of Pathobiology, University of the Poonch Rawalakot under the supervision of experts of the subject of pathology.

\section{Research design}

Total of two hundred sheep were selected for study purpose. They were divided in to two groups as adult group and young group on the basis of teeth and physical condition, 100 samples each of blood and livers of adult group of sheep were compared with 100 samples each of blood and livers from young animals.

\section{Serum biochemical analysis}

Table 1. Over all and cumulative scores of gross lesion

\begin{tabular}{|c|c|c|c|c|}
\hline \multirow[b]{2}{*}{ Organ } & \multirow[b]{2}{*}{ Lesion } & \multirow{2}{*}{$\begin{array}{c}\text { Maximum } \\
\text { possible } \\
\text { Score }\end{array}$} & \multicolumn{2}{|c|}{ Groups } \\
\hline & & & $\begin{array}{c}\text { Adult group of sheep } \\
(100)\end{array}$ & $\begin{array}{l}\text { Young group of } \\
\text { sheep }(100)\end{array}$ \\
\hline \multirow{7}{*}{ Liver } & Hepatomegaly & 12 & 10 & 8 \\
\hline & $\begin{array}{c}\text { Pale } \\
\text { discoloration }\end{array}$ & 12 & 10 & 6 \\
\hline & Friable & 12 & 12 & 8 \\
\hline & Hemorrhage & 12 & 12 & 6 \\
\hline & $\begin{array}{l}\text { Discovery of } \\
\text { flukes }\end{array}$ & 12 & 12 & 6 \\
\hline & $\begin{array}{c}\text { Bile duct } \\
\text { obstruction }\end{array}$ & 12 & 10 & 6 \\
\hline & Cholangitis & 12 & 10 & 8 \\
\hline $\begin{array}{c}\text { Cumulative score of } \\
\text { liver }\end{array}$ & & 144 & 76 & 48 \\
\hline
\end{tabular}

Samples of blood were collected from representative animals at the time of slaughter for evaluation of glucose, urea, triglycerides, uric acid, creatinine, alanine aminotransferases, aspartate aminotransferases, alkaline phosphatase, Gammaglutamyl transferases and serum total protein using commercially available kit of (AMEDA Labordiagnostik GmbH Germany).All the biochemical experiments were performed with Microlab-300.

\section{Statistical analysis}

Homogeneity (Levin's tests) and normality (Kolmogorov tests) tests were performed before analysis of data. Data was analyzed by one-way ANOVA. Data were considered significantly different when $P$ values were less than 0.05 .

\section{Results and discussion Clinical parameters}

Clinical signs and gross lesions of Fascioliasis were recorded from both groups of sheep before and after slaughter. A subjective evaluation of the gross lesions were performed based on the enlargement of liver, pale discoloration, friability, hemorrhages, discovery of extent of flukes, bile duct obstruction and cholangitis. The cumulative score of gross lesions in adult sheep were quite higher as compared to young sheep. The overall and cumulative score of gross lesions is depicted in (Table 1). 


\section{Serum biochemical analysis}

Blood glucose level was measured for both adult and young sheep groups. An increase in blood glucose in adult sheep was observed in comparison to young group of sheep.

During the present study significantly higher concentration of glucose was detected in aged animals aged animals in comparison to young animals similarly significantly lower level of creatinine was detected in aged animals as comparison to young (Figure 1). During the present study BUN and creatinine levels were significantly reduced in adult group of sheep as compared to young group of sheep. Results of less BUN in comparison with the young group of sheep (Figure 2).

Triglyceride level in the serum of sheep of two different groups was measured. It was observed that there is marked increase in concentration of triglycerides was noted in sheep of aged group, while triglyceride concentration was quite normal in the sera of sheep of young group (Figure 3).

A significantly decreased creatinine level correlates muscle loss due to availability of less protein which is helpful for reversal from anemia (Figure 4).

Serum biochemical parameters of adult animals were compared with young animals. When analyzing mean values of aged sheep with that of young group,apparently increased activity of serum ALT and AST $(\mathrm{P}<0.05)$ was noteded (Figure5 \&6). The serum liver AST, ALT and ALP levels were related with pathological changes, means higher the pathological lesions higher the values of AST, ALP (Figure 7) and ALT. Results are variable while comparing two groups.

To exclude malnutrition and other internal parasitism influence that cause hypoproteinemia other than hepatic origin, GGT was measured in both adult group and young group samples. The elevation of this enzyme in adult sheep group compared to young animals refers to elevation of this enzyme in chronic fascioliasis (Figure 8). The increase in GGT level in adult group is a very positive indicator of liver damage as compared to young animals.

Results of the present investigation affirmed effects of fascioliasis on total protein levels. The apparent decrease $(\mathrm{P}<0.05)$ in total protein (Figure 9) in sheep was due to the destructive effects of the parasite on hepatic parenchyma which lead to insufficiency in utilization and retention of serum total protein synthesis.

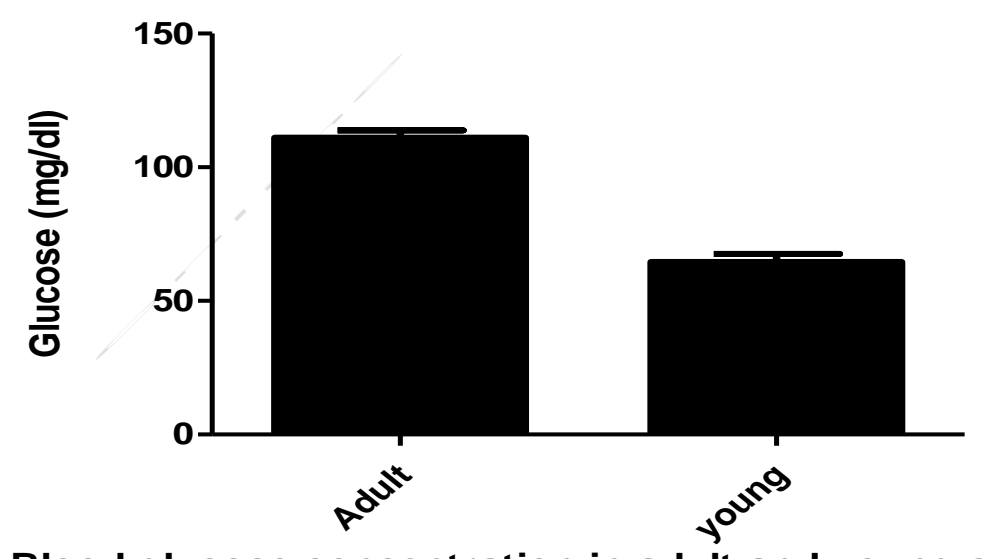

Blood glucose concentration in adult and young sheep

Figure 1. Blood glucose concentration in adult and young sheep $(P<0.05)$ in the concentration of blood glucose in adult and young sheep 


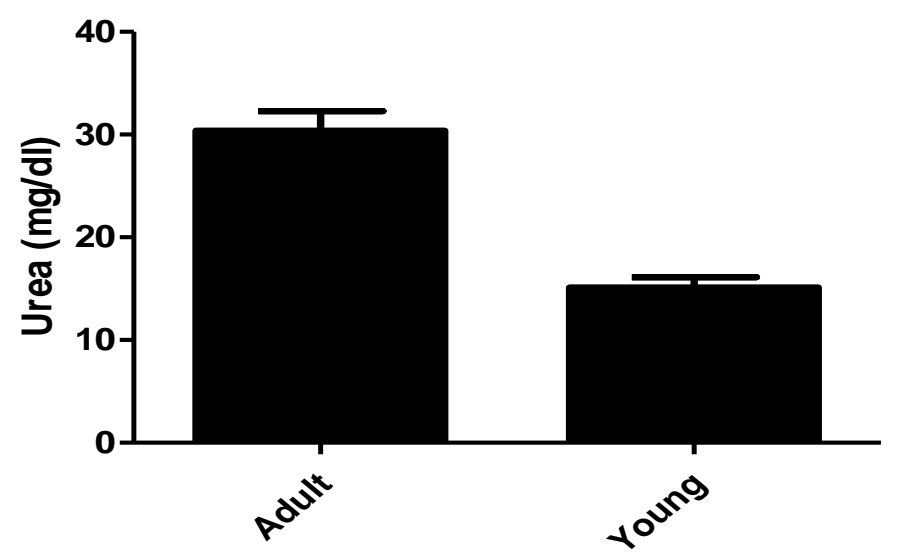

Urea concentration in adult and young sheep

Figure 2. Blood Urea Nitrogen concentration in adult and young sheep $(P<0.05)$ in the concentration of BUN in adult and young sheep

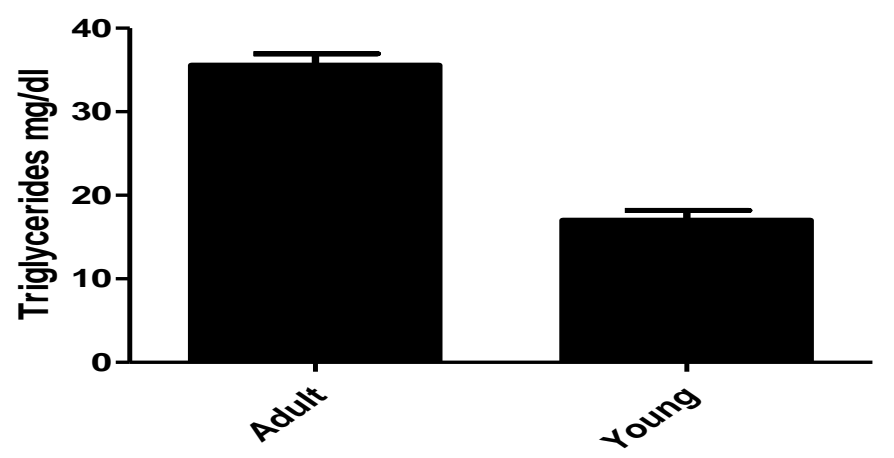

Triglycerides concentration in adult and young sheep

Figure 3. Triglycerides concentration in adult and young sheep $(\mathbf{P}<0.05)$ in the concentration of triglycerides in adult and young sheep

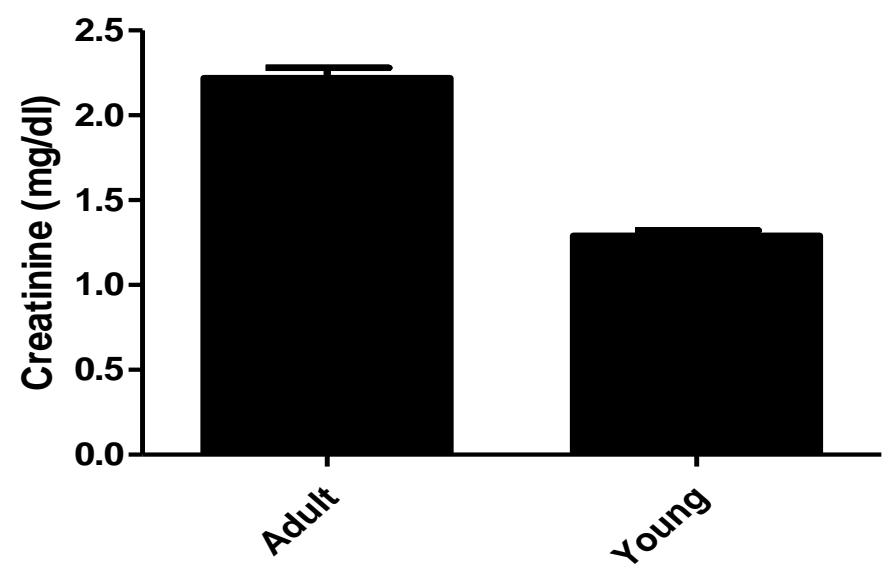

Creatinine concentration in adult and young sheep

Figure 4. Creatinine concentration in adult and young sheep $(\mathbf{P}<0.05)$ in the concentration of creatinine in adult and young sheep 


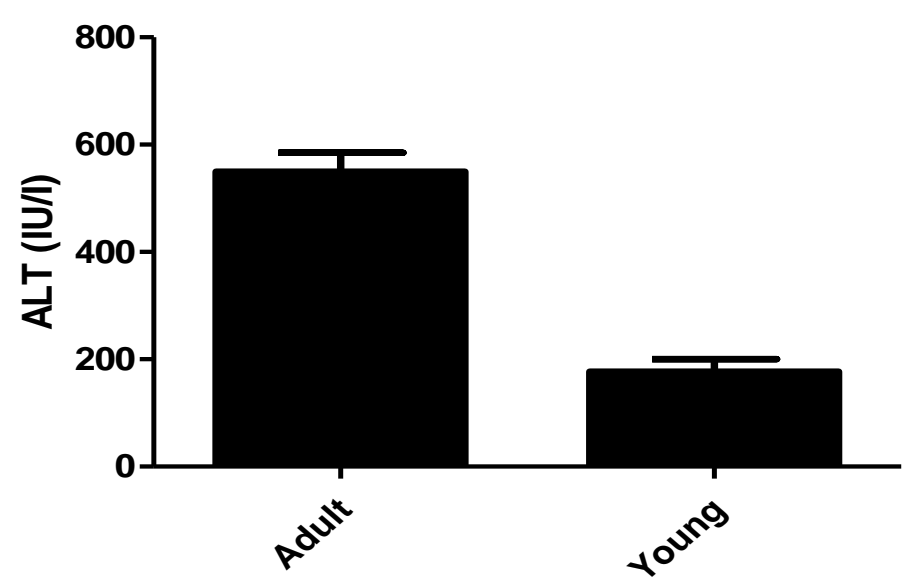

ALT values in adult and young sheep

Figure 5. ALT values in adult and young sheep $(P<0.05)$ in the values of ALT in adult and young sheep

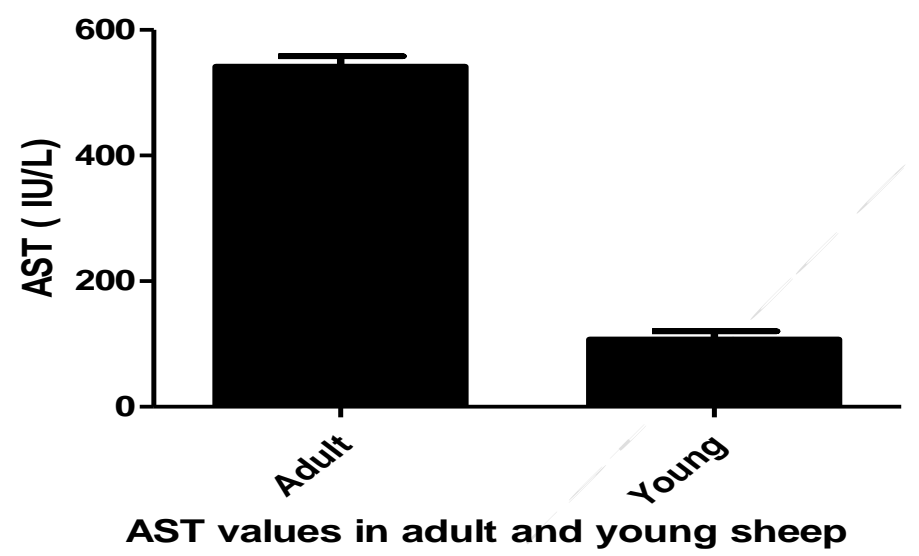

Figure 6. AST values in adult and young sheep $(P<0.05)$ in the values of AST in adult and young sheep

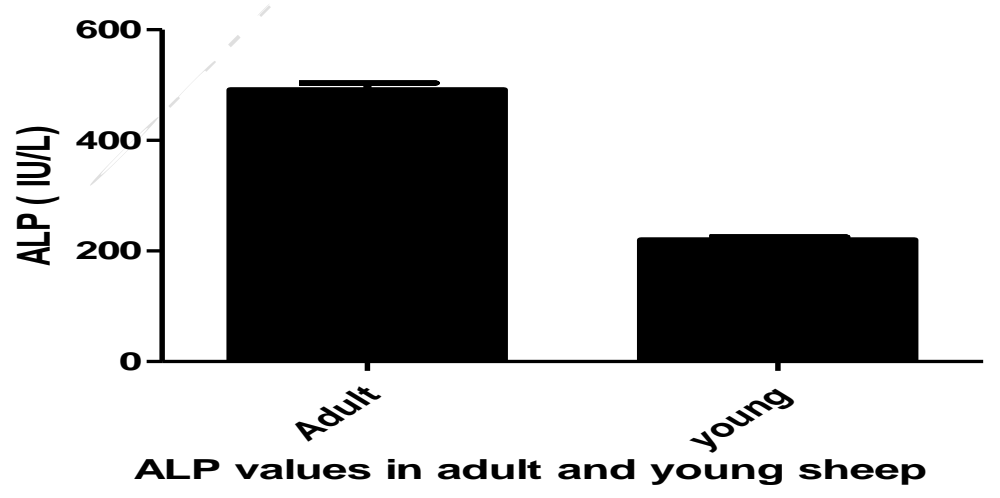

Figure 7. ALP values in adult and young sheep $(P<0.05)$ in the values of ALP in adult and young sheep 


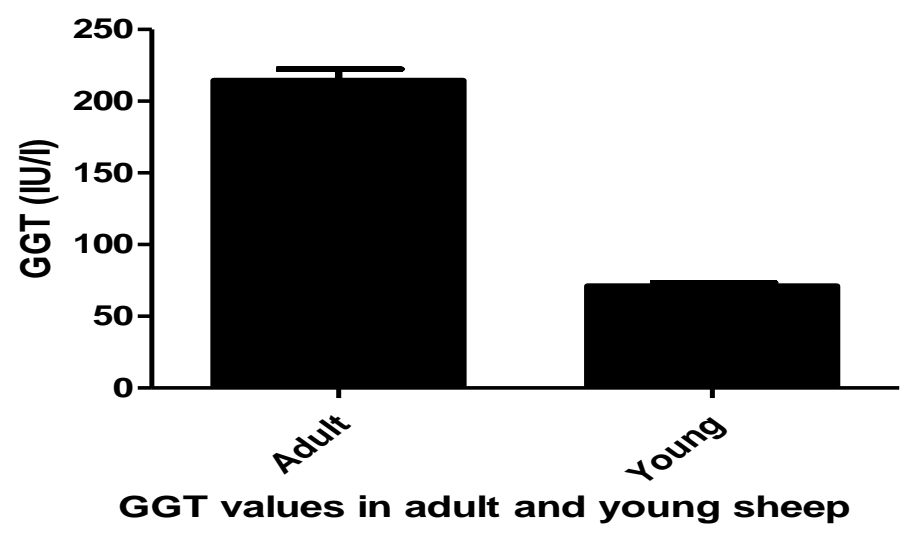

Figure 8. GGT values in adult and young sheep $(P<0.05)$ in the values of GGT in adult and young sheep

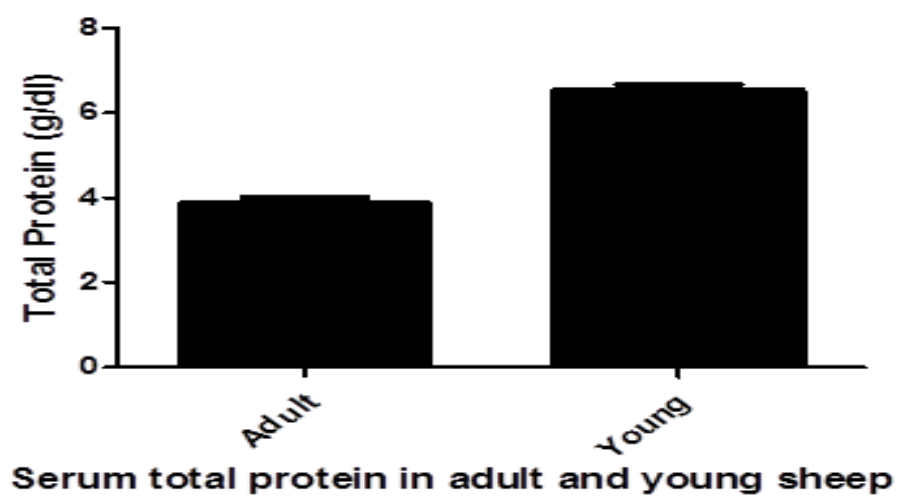

Figure 9. Serum total protein in adult and young sheep $(P<0.05)$ in the values of serum total protein in adult and young sheep

\section{Recovery of liver fluke}

Entire liver representative samples were kept in a dissection tray and incision was made deeply so that blood vessels were exposed from portal vessels, gall bladders and bile ducts. Liiver flukes were kept outside with precautions in order to avoid damage. Recovered parasites were were washed thrice in normal saline and then fixed informaline acetic alcohol.

\section{Gross and histopathological studies}

Carcasses from both the groups of animals showed extreme degree of paleness, marked icterus, andoedema in submandibular region. Grossly there was inflammation of peritoneum, extensive deposition of thick fibrous tissues and exudates with fibrin as a dominant feature. After necropsy representative tissue samples were collected in $10 \%$ neutral buffered formaline for further study. Histopathologically changes were noted specific for acute fasciolosis. Outermost layer of the bile duct was hyperProliferative with discovery of immature flukes in them. Livercelss were dead, black and weak with infiltration of inflammatory cells. Hemorrhages in the liver parenchyma were noticed in the form of focal areas while migration of flukes.Histopathologically liver of aged sheep showed less number of liver cells and lesser sinusoids (Figure 10), mononuclear cellular infiltration in portal 
region was noted. Hepatic cords were disorganized, with proliferation of connective tissues in bile ducts. There were some areas of congestion with death of cells of parenchyma and degeneration along with vacuolation of liver cells in central area in young sheep (Figure 11). In case of severe infection accumulation of water and increased neutrophils were noticed in livers.

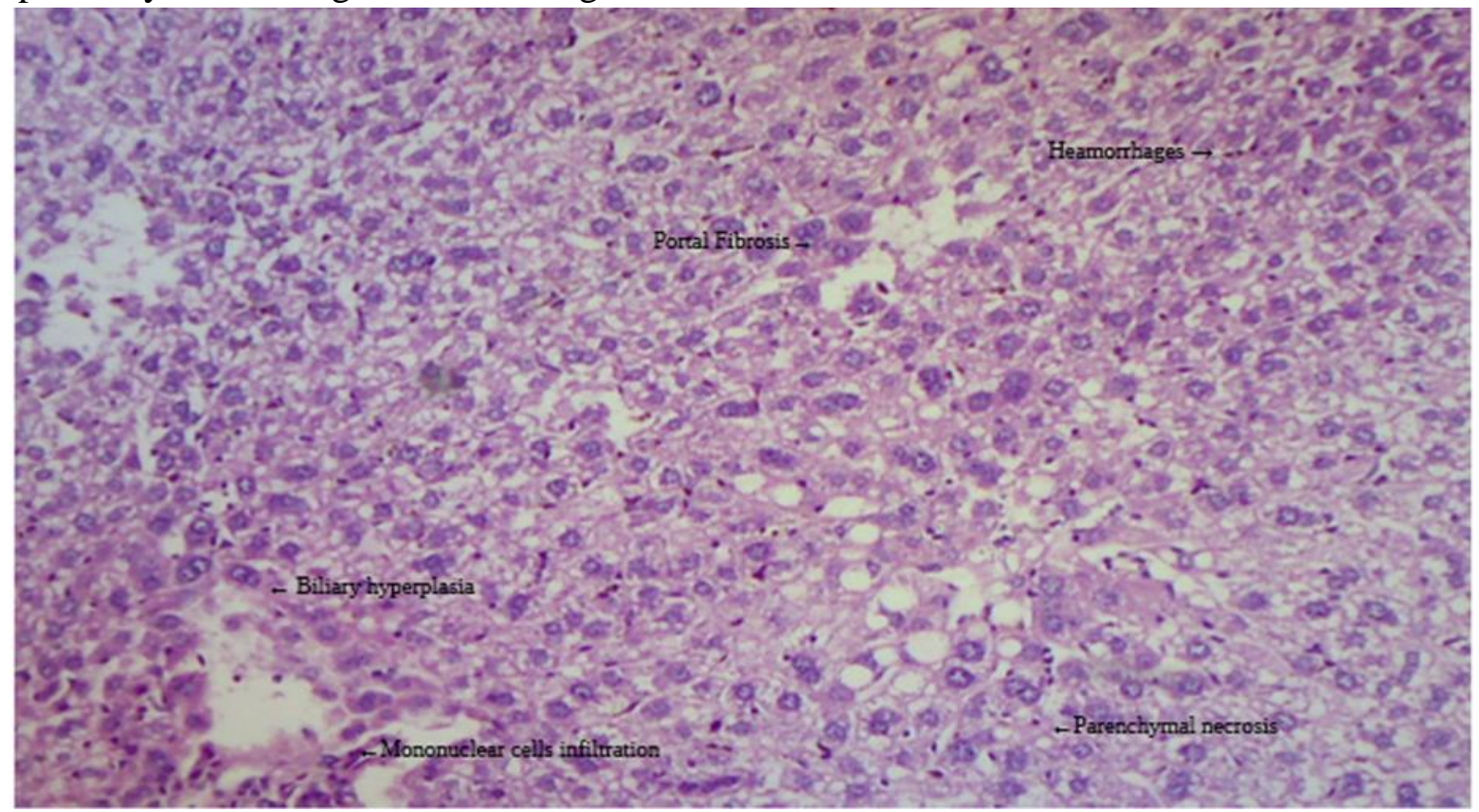

Figure 10. Histopathological changes in the liver of sheep of adult group

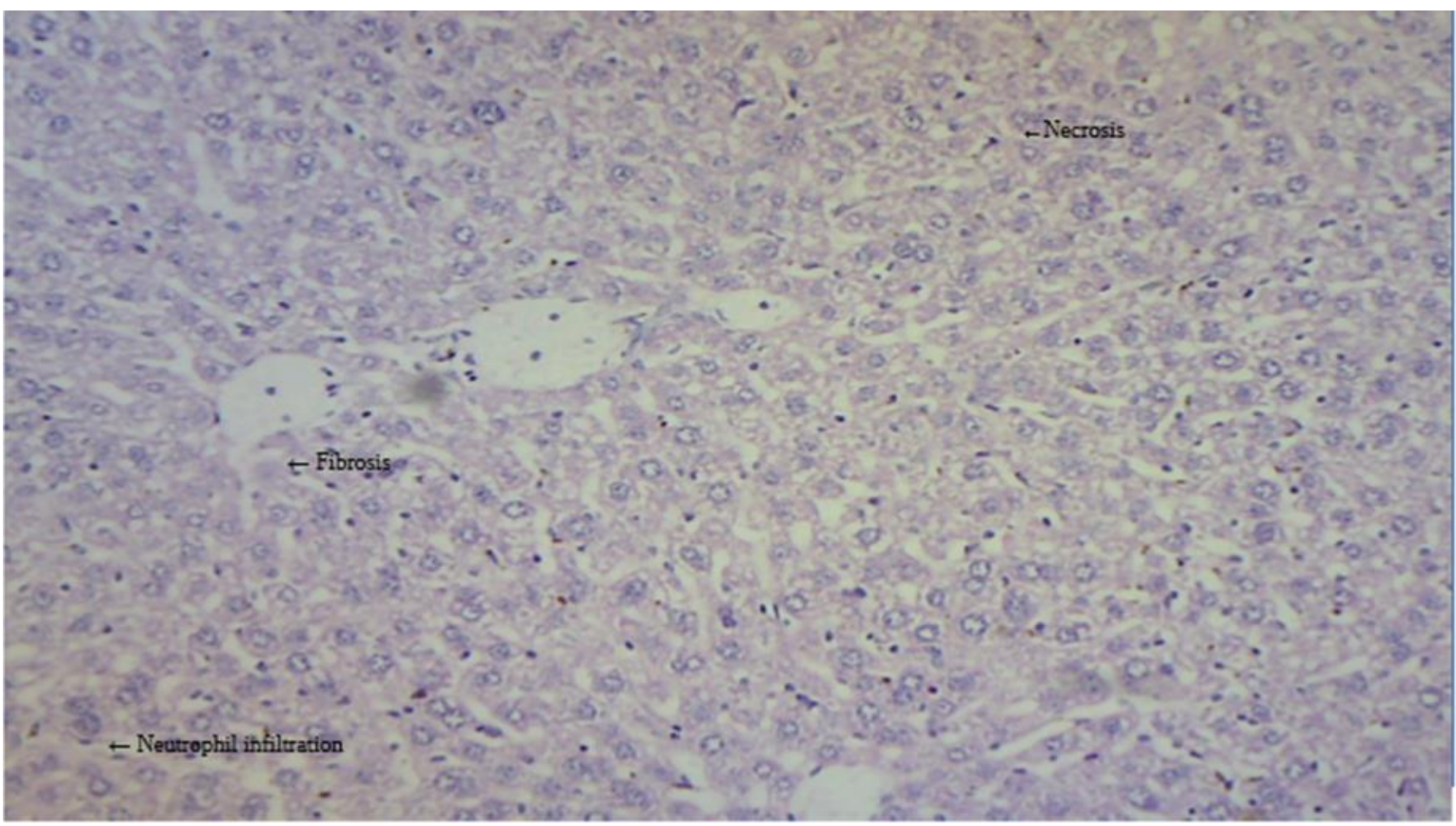

Figure 11. Histopathological changes in the liver of sheep of young group 
During this study, macroscopic pathological changes noticed in liver of sheep were identical except with some areas of calcification were observed in aged sheep livers.Macroscopic lesions in the form of hard, icteric and hard consistency of liver were observed. In prolonged cases variable sized livers, nodular areas, petechial hemorrhages were also observed on parietal surface of liver.Bile duct was thickened and distended (Figure 12). In severe cases hepatomegally, icteric liver with hemorrhages on parietal surface.

Both parenchymal and biliary tract changes were noted in this study. Fibroblasts, lymphocytes, plasma cells and macrophages were also present in the affected area with mild fibrosis (Figure 11) and biliary hyperplasia were lesions repeatedly examined in chronic cases.

Microscopically the biliary tract has showed less changes than liver parenchyma in acute form of the fluke infection. Routes of migration of flukes were infiltered with macrophages and eosinophils (Figure 11). Multifocal hepatitis and the necrotic lesions with deep eosinophilic cytoplasm, karyorhexis and karyolysis were examined.

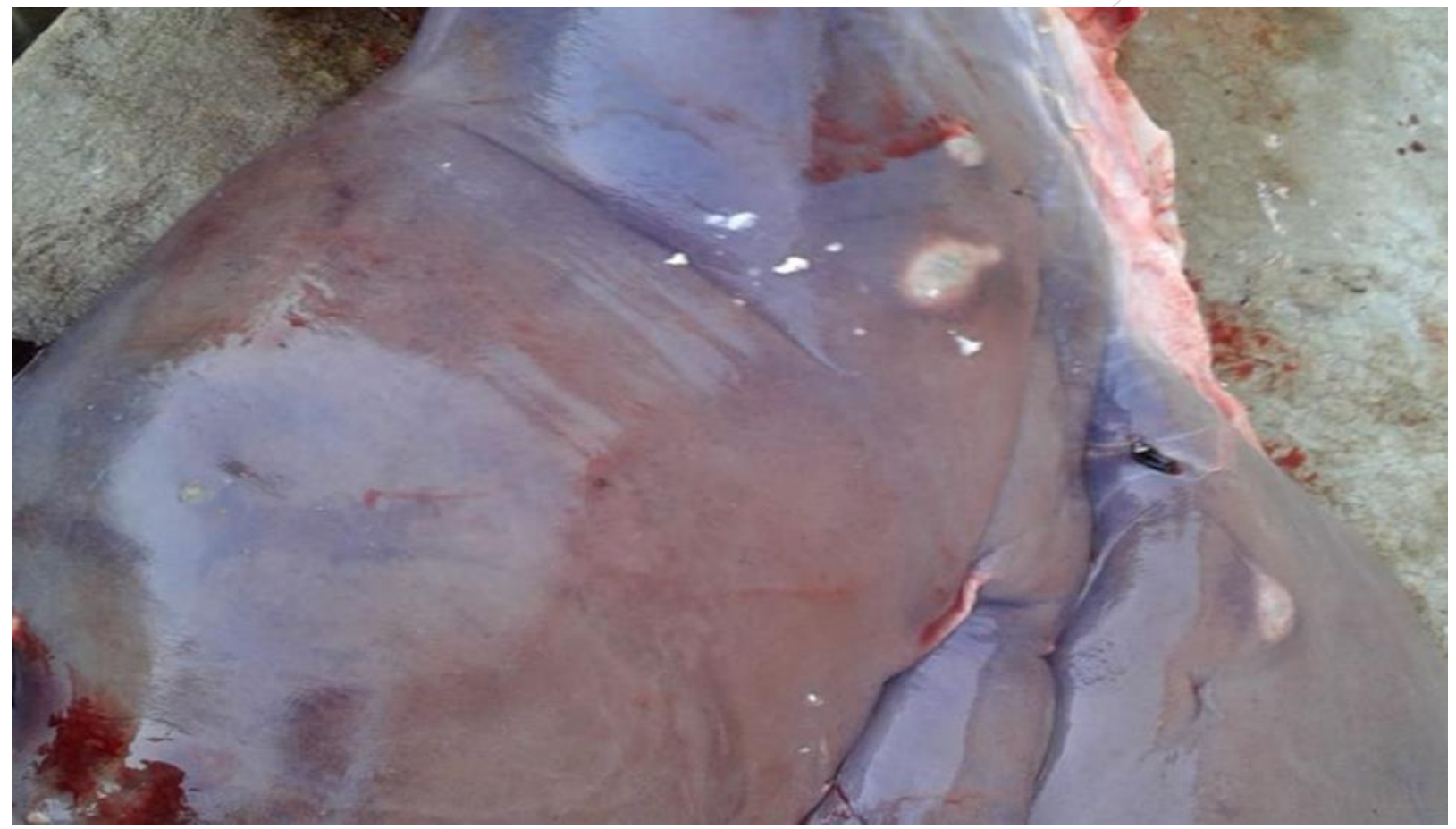

Figure 12. Grossly affected liver of sheep with Fasciolosis

\section{Discussion}

This is the first ever study about fasciolosis, in which comparison was made between aged and young sheep in AJK. This is a fact that sheep housed in farms are much prone to parasitic infestations as compared to those kept on lush green pasture with no supplementation of feed whereas, sheep in conventional rearing systems, given feed higher in protein, have well developed immunity in order to combat the parasitic burden. In addition, such data is very difficult to compare in between conventional system of rearing and to sheep housed in organic farms. During the study, sheep from both aged and young group were included for study on the basis of clinical, biochemical, histopathological examination. In this study, histopathological and biochemical parameters in the infected young and adult 
sheep were studied, most of the parameters in aged sheep higher than normal, whereas they are quite normal in young sheep inspite of presence of flukes in their body possibly because of their strong immunity and this study is in line with $[9,10]$, except for the concentration of albumin and BUN which were slightly elevated probably as a result of grazing on forage legumes.

\section{Clinical parameters}

Oedema of the sub mandibular region was noticed in almost both aged and young sheep. Macrscopic pathological changes exhibited in the form of hepatomegaly, ictericness of liver, friable color of liver, hemorrhages, discovery of extent of flukes, bile duct blockage and cholangitis in aged sheep while intensity of infection was quite less in young animals, these findings are in close agreement with the report of [11], as they studied hemorrhages on the parietal surface of the liver in prolong edfasciolosis from sheep farm. There were patches of hemorrhages on the site of entry of immature parasites in the liver parenchyma [12]. In line with report of [13-15], prolonged infections of the present study showed that the livers were hard, tough in consistency and some of the areas were calcified similarly infected bile ducts were showing inflammation with discovery of flukes from bile ducts. There is possibility that it was due to immunological reaction of macrophages and lymphocytes infiltration that combine with fibrotic healing of the necrotic areas during the chronic stage of fasciolosis. Continuous irritation by the adult flukes in the biliary tract cause biliary inflammation like hyperplastic cholangitis, ductular wall thickening, and intra- and extrahepatic biliary dilatation $[16,17]$.

\section{Serum biochemical analysis}

This study has revealed that there was rise in the serum level of glucose, urea, creatinine, triglycerides, ALT, AST, ALP and GGT in aged group of sheep while significant reduction in the serum total protein in aged sheep was observed, whereas in young sheep serum biochemical profile remain unchanged.

Our findings showed that biochemical profile including blood glucose, liver enzymes (AST, ALT,ALP, GGT), urea and creatinine were significantly high $(\mathrm{P}<0.05)$ and there was reduction in total protein $(\mathrm{P}<0.05)$ in infected aged sheep in comparison with young sheep. These results are in close confinement to those studied by [18], who demonstrated a significant rise in enzyme levels in infected sheep and goats [19]. [20] Studied an increase of AST levels 2 weeks after infection in conjunction with migratory immature flukesin the liver parenchyma. They narrated that damage to liver is a contributing factor for rise of serum ALT activity in the infected sheep.

As it is evident that Fasciola spp. are responsible to induce the release of reactive oxygen species that produce damage to cell membrane and hepatic tissue death. These pathological alterations direct influence on biochemical profile in serum including liver specific enzymes [21]. As there is a difference in activities of liver enzymes like AST, ALT, GGT, ALP, Triglycerides in serum are generally indicative of pathological changes of tissue and organ [22]. In line with the results of the this study showed a variation in ALT, AST and ALP values between cattle, sheep and goats affected by different stages of fasciolosisas compared with animals with no fasciolosis. Whenever the liver is injured or damaged, the liver enzymes leak into the blood, resulting in increase of serum liver enzyme [23].

Several studies showed very little or no effect of fasciolosis on feed intake [24] and BUN $[25,26]$, the results of significantly higher BUN in comparison with the young sheep indicate a need for protein metabolism estimation during chronic fasciolosis. 


\section{Gross and histopathological studies}

Larval migration to the liver, especially in sheep, leads to serious consequences. This migration causes hemorrhage and fibrosis in the hepatic parenchyma. Morbidity of infection in ruminants is high and mortality in lambs is reported [27]. The condition of hepatitis cysticercosis, caused by C. tenuicollis in sucking pigs, was described by [28-30]. [31] Observed hemorrhagic wavy tracts on in the cortex of the liver of lambs that were experimentally infected with this parasite. In another study [32], on pathological investigation concluded that, the liver showed haemorrhagic, thickening of the Glisson's capsule and inflammatory reaction in the vicinity of the cyst. In the present study, the infected goats with $C$. tenuicollis, indicated large concentric foci of hemorrhage at the surface of liver at necropsy. In histopathological examination, decreased number of hepatocytes, dilution of sinusoids, presence of inflammatory cells in portal areas and double layered parasitic cyst formation in chronic stages were evident.

\section{Conclusion}

Fascilosis caused marked pathological alterations in the liver of both adult and young sheep. It was concluded that liver fluke infestation in sheep induced elevated levels of liver enzymes along with increased glucose, triglycerides and creatinine. Fascilosis caused marked reduction in serum total protein in adult sheep. Pronounced histopathological changes in the form of hemorrhages, necrosis, hyperplasia, fibrosis and mononuclear cells infiltrations were also noted in adult sheep.

\section{Authors' contributions}

Conceived and designed the experiments; SA Khan \& N Ahmed, Performed the experiment; SA Khan \& N Ahmed, Analyzed the data; SA Khan, Contributed reagents/ material/analysis tools; SA Khan \& N Ahmed, Wrote the paper: SA Khan, N Ahmed \& T Tunio.

\section{References}

1. Iqbal Z, Hayat B \& Khan MN (1986). Studies on the seasonal prevalence of fascioliasis and lungworm disease in sheep at Faisalabad. Pak Vet $J$ 6: 131-134.

2. Spithill TW, Smooker PM \& Copeman DB (1999). Fasciolagigantica: Epidemiology, control, immunology and molecular biology. In Fascioliasis (Ed. Dalton JP). CAB International Oxford pp. 465-525.

3. Nawaz M \& Nawaz Y (1987). Problem of fascioliasis in sheep and goats in the province of Baluchistan, Pakistan. Proc Pak Congr Zool 7: 84-85.

4. Njeruh FM, Kithuka JM, Maingi N \& Ombui JN (2004). Prevalence and economic importance of fascioliasis in cattle, sheep and goats in Kenya. Kenya Veterin 27(1): 118-123.

5. Ardo MB, Aliyara YH \& Lawal H (2013). Prevalence of Bovine Fasciolosis in Major Abattoirs of Adamawa State, Nigeria. Bayero J of Pure and Appl Sci 6(1): 12-16.

6. Uduak A (2014). Incidence of bovine fasciolosis and its economic implications at Trans-Amadi abattoir Port-Harcourt, Nigeria. ActaParasitolGlobalis 5: 206-209.

7. Oladele-Bukola $\mathrm{M}$ \& Odetokun IA (2014).Prevalence of Bovine Fasciolosis at the Ibadan Municipal Abattoir, Nigeria. African J of Food, Agric, Nutri and Devel 14(4):9055-9070.

8. Leong ASY (1994). Fixation and fixatives, in Laboratory histopathology, a complete reference (Woods, AE, and Ellis, RC, Eds), Churchill Livingstone, New York, 1: 4.11/4.2-26.

9. Kramer JW (2000). Normal hematology of cattle, sheep and goats. pp 1075-1084.

10. Kaneko JJ, Harvey JW, Bruss ML (1997) Clinical Biochemistry of Domestic Animals, 5th edn. Academic, San Diego, pp 890-894.

11. Okaiyeto SO, Salami OS, Dnbirni SA, Allam L \& Onoja II (2012). Clinical, Gross and Histopathological Changes Associated With Chronic Fasciolosis Infection in a Dairy Farm. J Vet Adv 2(8): 444-448.

12. Borai MGE, Abdel-Rehiem A, Nagi MS, Gab-Allah AB, ElMashadI \& Shawky AM (2013) Comparative pathological studies on 
parasitic affections of liver in farm animals. BenhaVeter Med J 25(2):284-295.

13. Jones EA, Kay JM, Milligan HP \& Ownez D (1977). Massive infection with Fasciofa hepatica in man. Am. J. Med 63: 803-842.

14. Molina EC, Skerratt LF, Campbell R (2005). Pathology of fasciolosis in large ruminants. Overcoming liver fluke in South East Asia. pp 94-126.

15. Sayed SM, GehanMS \&Neveen AE (2008). Clinicodiagnosticstudies on hepatic affections of aged buffaloes. Assi VE T med J 54(117): 310-328.

16. Catalano OA, Sahani DV, Forcione DG, Liu CB, Hsien C, Soricelli A, Arellano RS, Muller PR \& Hahn PF (2009). Biliary infections: Spectrum of imaging findings and management. Eur JPediatr 29(7): 2543.

17. Khan SA, Muhammad S, Khan MM \& Khan MT (2015). Study on the prevalence and gross pathology of liver fluke infestation in sheep in and around Quetta District, Pakistan. AdvAnim Vet Sci 3(3): 151-155.

18. Pathak KML, Gaur SNS \& Sharma SN (1982). The pathology of Cysticercustenuicollis infection in goats. Vet Parasitol 11:131-139.

19. Doaa FT, SolimanEK \&Abd El-Khalek TMM (2007). Effect of Fascioliasis on hematological, serum biochemical and histopathological changes in sheep. Egypt $J$ Sheep Goat Sci 2(2): 15-34.

20. Singh J, BalM, Aradhana S \& Gumber S (2004). Efficacy of different flukicides against fascioliosis in sheep and goats. $J$ Res 41(2): 287-289.

21. Hodzic A, Zuko A, Avdic R, Alic A, Omeragic J \&Jazic A (2013). Influence of Fasciolahepatica on serum biochemical parameters and vascular and biliary system of sheep liver. Ira.

22. Tanritanir P, Ozdal N, Ragbetli C, Yoruk I, Ceylan E \&Deger S (2009). Some biochemical parameters and vitamins levels in the hair goats naturally mixinfested with ectoparasites (Lice (Linognathusafricanus) and Trichostrongylidae spp.). J Vet $A d v$ 8(3): 590-594.

23. Mert H, Kozat S, Ekin S \&Yörük I (2006). Serum sialic acid, lipid-bound sialic acid levels in sheep naturally chronic infected with $F$ hepatica. SAG Bilim Der9:40-46.

24. Akinbamijo OO, Lahlou-Kassi A \&Tembely $S$ (1996). Effect of experimental fascioliasis on feed intake, nitrogen retention and body weight changes in open and pregnant Menz sheep. Small Rumin Res 20: 163-169.

25. Anderson PH, Berret S, Brush PJ, Hebert CN, Parfitt JW \& Patterson DS (1977).Biochemical indicators of liver injury in calves with experimental fascioliasis. Vet Rec 100: 43-45.

26. Sykes AR, Coop RL\& Rushton B (1980). Chronic subclinical fascioliasis in sheep: effects on food intake, food utilisation and blood constituents. Res Vet Sci 28(1):63-70.

27. Soulsby EJL (1986). Helminths, arthropods and protozoa of domesticated animals, 7th edn. Baillier Tindall, London, pp 113-115.

28. Bertullo VH (1943). Hepatitis cysticercosa de loslechonesocasionadaper el Cysticercustenuicollis de la Taeniamarginata. Bul Min Direction Gana Montevideo 27: 429-434.

29. Lloyds TS (1964). Hepatitis cysticercosa causing sudden death in a pig. Vet Rec 10761080 .

30. Karasev NF (1978). Distribution, clinical manifestation and pathology of Taeniahydatigena and Cysticercustenuic ollis in animals in Belorusia. Dostizh Vet Nulki Peredovog Zhivotnov 55: 77-79.

31. Pullin JW (1955). Observation on the liver lesions in lambs experimentally, with cysticerci of Taeniahydatigena. Med Vet Sci 19:48-49.

32. Darzi MM (2002). Pathology of Taeniahydatigenacysticercosis in a naturally infected Corriedale lamb. Vet Parasitol 16(2): 173-174. 